EL IMPACTO DEL ABOLICIONISMO Y/O

REGLAMENTARISMO EN LA VIDA COTIDIANA

DE MUJERES EN SITUACIÓN DE

PROSTITUCIÓN. SANTA ROSA LA PAMPA,

AÑO 2015

The impact of abolitionism and/or reglamentarism in the

daily life of women in prostitution. Santa Rosa La Pampa, 2015

\title{
Carolina Folmer
}

Universidad Nacional de Villa María

\begin{abstract}
Resumen
El presente artículo se desprende de un trabajo final de grado para la Licenciatura en Trabajo Social y se propone analizar y reflexionar sobre las experiencias de mujeres en situación de prostitución en el año 2015 en la ciudad de Santa Rosa, a la luz de los paradigmas abolicionista y/o reglamentarista. De esta manera se busca conocer los significados que atribuyen las mujeres a la práctica de la prostitución y las relaciones que se dan en ella.
\end{abstract}

Palabras Claves: prostitución - abolicionismo - reglamentarismo

\begin{abstract}
Abstrac:
This article follows a final degree for the Bachelor of Social Work and intends to analyze and reflect on the experiences of women in prostitution in 2015 in the city of Santa Rosa, in light of the abolitionist paradigms and/ or regulationist. In this way it seeks to understand the meanings attributed women to practice prostitution and relationships that occur in it.
\end{abstract}

Key words: Prostitution - abolitionism - reglamentarism

Sumario: Introducción a la problemática de la prostitución. Comienzos en la prostitución. Un Estado Proxeneta. El patriarcado como organizador de la vida familiar. Encuentro con el prostituyente. Reflexiones sobre la prostitución como trabajo. Reflexiones finales. 


\section{Introducción en la problemática de la prostitución}

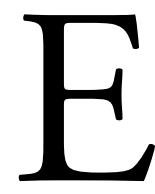

n el presente proyecto, se concibe a la prostitución como la venta de servicios sexuales a cambio de dinero o cualquier otro bien (OMS 1989). El término prostitución proviene del latín "prostituere", que significa "exhibir para la venta”. En este ámbito, la mayoría de las personas prostituidas son mujeres pero también existen travestis, hombres, niños y niñas en menor proporción; asimismo, los mayores consumidores de prostitución como de explotación son hombres.

La dinámica del capitalismo configura un contexto social que estructura a los sujetos, las relaciones y la vida cotidiana en general. Según datos de la CEPAL (2012) la pobreza sigue en disminución en América Latina pero aún afecta a 167 millones de personas. Las cifras indican que el 10\% más rico de la población latinoamericana recibe el $32 \%$ de los ingresos totales, mientras que el $40 \%$ más pobre recibe solo el $15 \%$. De esta manera la salud de las mujeres se ve influida de manera definitiva por factores sociales y económicos, como el acceso a la educación, el nivel de riqueza familiar y el lugar de residencia. La violencia es otro riesgo importante para la salud sexual y reproductiva de las mujeres ya que puede ocasionar trastornos mentales y otros problemas crónicos de salud (OMS 2009).

A pesar de los grandes avances que ha logrado la mujer en la sociedad, la igualdad de género es uno de los grandes desafíos de estos tiempos. Aún para muchas mujeres y niñas la discriminación, la desigualdad, la violencia y la privación de derechos son una realidad diaria.

Joan Scott (1990) ha profundizado el concepto de género desde una perspectiva histórica. Permite pensarlo como elemento fundamental en la organización social de las relaciones, destacando que se refiere a las relaciones construidas entre los sexos (hombre y mujer).

La autora afirma que por un lado, el género es un elemento constitutivo de las relaciones sociales basadas en las diferencias que distinguen los sexos y, por otro lado el género es una forma primaria de relaciones significantes de poder.

Según estadísticas de la OMS (2009) la violencia contra la mujer está generalizada en todo el mundo. Las mujeres que han sido víctimas de abusos físicos o sexuales presentan tasas más elevadas de enfermedad mental, embarazo no deseado y aborto, tanto espontáneo como inducido, que las que no han sufrido esos abusos. La mayoría de las agresiones contra las mujeres son cometidas por varones con los que tienen una relación íntima. Recientemente se ha comenzado a visibilizar la violencia sexual como táctica de guerra. 
La convención para la Eliminación de la Violencia contra la Mujer, ratificada por Argentina en el año 2000, otorga un marco legal para manifestarse en contra de todas aquellas acciones $\mathrm{u}$ omisiones que vulneren los derechos humanos fundamentales para las mujeres. Sin embargo dentro de este sistema, el patriarcado se presenta como el escenario donde las relaciones desiguales de poder pueden llegar a hacerse reales y desarrollarse sin inconvenientes.

El término "patriarcado" es conceptualizado como un sistema de relaciones sociales sexo-políticas basadas en diferentes instituciones públicas y privadas y en la solidaridad interclases e intragénero instaurado por los varones, quienes como grupo social y en forma individual y colectiva, oprimen a las mujeres también en forma individual y colectiva y se apropian de su fuerza productiva y reproductiva, de sus cuerpos y sus productos, ya sea con medios pacíficos o mediante el uso de la violencia. Los estudios feministas sobre el patriarcado, y la constatación de que se trata de una construcción histórica y social, señalan las posibilidades de cambiarlo por un modelo social justo e igualitario (Fontela 2004).

Es así, como desde la organización patriarcal, se construye una determinada sexualidad masculina y femenina que avala y legitima la desigualdad de género. En consecuencia, la sexualidad debe dejar de ser entendida como manifestación de un instinto natural y un destino biológico y poder concebirla como una construcción social e histórica (Elizalde, Felitti y Queirolo 2010).

Desde la perspectiva de género en el complejo fenómeno de la prostitución, las relaciones que se desarrollan en ella se fundan en la desigualdad de género, la mayoría de las personas que son prostituidas son mujeres y la mayoría de personas que consumen son hombres.

María Lourdes Molina (2008) señala que existen distintas miradas con respecto a las personas en situación de prostitución:

a) Mirada Prohibicionista: Pretende eliminar de la sociedad el ejercicio de la prostitución. Establece la represión penal ante cualquier oferta sexual pública o privada que implique una retribución monetaria. La mujer que esta en prostitución se torna en una "delincuente" y debe responder ante la justicia sobre su conducta, lo que puede originar castigos que van desde el encarcelamiento hasta multas o medidas reeducadoras para quien la ejerce, organiza o promueve.

b) Mirada Reglamentarista: Considera a la mujer prostituida como una trabajadora sexual, cuya actividad debe ser controlada por el Estado. Consideran que la prostitución se debe reglamentar porque es la forma más idónea de defender los derechos de las mujeres prostituidas. 
c) Mirada Abolicionista: Realiza una crítica radical a la prostitución como fenómeno social, cuestionando la estructura que subyace de subordinación y explotación sexual de la persona prostituida.

\section{Comienzos en la Prostitución}

Interpretar el comienzo en la prostitución solo en términos de libertad de elección ofrece una imagen distorsionada y sesgada de la complejidad de la problemática. A continuación, se ofrecen testimonios de mujeres ${ }^{1}$ que describen escenarios sociales con características comunes o similares que es imposible dejar de lado a la hora de las interpretaciones. Todas ellas afirman que comenzaron entre los años 2000 y 2002, y en este escenario se hace imposible no mencionar que en esos tiempos la política del Estado Argentino no buscaban la garantía de los derechos sino que, provocaron la fragmentación y exclusión social de amplios segmentos de la población.

El comienzo en la prostitución se presentó como única opción ante un horizonte pobre de oportunidades, y en un contexto donde la explotación sexual ya estaba naturalizada en el seno de la vida familiar. La combinación de familia numerosa, precariedad laboral y entornos de violencia resultan un "combo" de fragmentación familiar y exclusión social que impulsan a las mujeres al mundo de la explotación sexual. De esta manera, los escenarios sociales en los que se encontraban condicionaban la decisión de comenzar en la prostitución.

Las mujeres lo relatan de esta manera:

...Cuando yo me separé, me separé porque él me mataba a palos y cuando lo sacaron de mi casa...y después viene todo esto de la prostitución. Entonces decidí quedarme sola, pase frio, pase hambre, de todo. Yo tenía a mi hermana que ejercía la prostitución, y ella me dijo, Sonia vos estas pasando esto porque vos querés, y me dice ¿por qué no lo dejas al plan? tengo un amigo que si vos querés salir te paga...tenés que acostarte con él y te paga. Y Mirta me dice si es un ratito pero que se cuide, no vayas a hacer nada que vos no quieras. Si el tipo te quiere hacer cosas decile que te dé más plata (Sonia 2015).

...Llegué a la prostitución por necesidad....alquilábamos, el papá de los nenes trabajaba de changas...Yo a veces necesitaba plata, lo básico lo teníamos, pero yo a veces veía que la hermana de él (que ejercía la prostitución) le compraba a los chicos de ella, en cambio

1 La muestra que se seleccionó para este trabajo de investigación fueron 4 mujeres que estuvieron o están en situación de prostitución ya sea en la vía pública o en ámbitos privados y además residen en la ciudad de Santa Rosa. 
ellos me pedían algo y yo no se lo podía comprar al no tener trabajo ni siquiera cobraba salario ni nada... (Marta 2015).

Tenía una amiga Tucumana (Tamara) a quien conocí porque vivía en el barrio de mi tía con su Marido. Un día, le conté por todo lo que estaba pasando con el padre de Demian y le dije que me quería ir lejos de mi casa; en ese momento, Tamara me habla de la oportunidad de trabajar en un bar de acá de La Pampa y que podíamos hacer buena plata juntas... Todavía no había cumplido los 2. En ese momento, venía a Santa Rosa, me hacía unos mangos y me volvía a La Rioja. Después de un tiempo, me vine definitivo (Soledad 2015).

Mi hermana más grande había empezado la calle antes que yo...lo hacía por su familia. Todos empezamos cuando aprieta el bolsillo, cuando no tenés para darle de comer a tu familia, o cuando no tenés para comprar los medicamentos para tus hijos (Patricia 2015).

Las mujeres entrevistadas narran que en medio de este escenario de soledad, estar en prostitución presentaba diferentes ventajas. Una de ellas es la facilidad en la flexibilidad del tiempo y espacio, generalmente realizaban la actividad durante la noche cuando sus hijos dormían y de esta manera no requerían contratar una niñera o acudir a los favores de algún familiar. También les permitía, cumplir con las actividades del hogar y de sus hijos. Otra de las características importantes de la prostitución es que no se requiere una formación específica ni formal y tampoco se necesita dinero para ingresar en el mercado de la explotación sexual, y lo más importante, es que les permitía tener el dinero al instante.

\section{Un Estado Proxeneta}

El Estado Proxeneta es aquel que mantiene a las personas en situación de explotación otorgando tarjetas, cajas alimentarias, subsidios esporádicos pero no brinda una ayuda radical para salir de la situación de prostitución (Sánchez 2007).

Es oportuno considerar que las historias de las mujeres entrevistadas se encuentran atravesadas por una evidente ausencia del Estado en todas las esferas de su vida. Sus historias no son hechos aislados sino que están vinculadas a la historia de la Argentina, con el rol que ocupó el Estado desde mediados de los años 70 con sus políticas neoliberales, como se fueron profundizando en los años ' 90 y como se terminaron de consolidar con el estallido de la crisis social que se vivió en 2001.

Las transformaciones de las políticas públicas en Argentina tienen dos periodos históricos claves, por un lado el Estado de Bienestar a mediados del siglo pasado, y 
por otro, los avances de las políticas neoliberales que se profundizaron en la década del 90 barriendo con todas las conquistas sociales logradas en la etapa anterior.

"En la década de 1990, con la asunción del Presidente Carlos Menem, se produce la reforma del Estado. De manera similar a otros países de la región, las políticas de ajuste estructural se basaron en una estricta aceptación de las propuestas de los organismos internacionales de financiamiento como el FMI, Banco Mundial entre otros, en lo referente a la desregulación de la economía y los mercados, apertura externa, privatización de las empresas públicas de servicios de uso económico masivo y productivas estratégicas, cambios profundos en la legislación laboral tendientes a la flexibilización, modificación de la orientación de las políticas públicas y del rol social y económico del Estado. A partir de la desregulación del mercado, el sector privado comienza a ocuparse de los servicios básicos como educación, salud, obras sociales, pensiones, jubilaciones, riesgos de trabajo, entre otros. La política social del Estado Neoliberal tenía como objetivo fundamental atender las situaciones de pobreza extrema, lo cual implicaba el abandono de otros objetivos como la reducción de la incertidumbre, la distribución progresiva de los ingresos y la movilidad social" (Lo Vuolo et al, 2002 citado en Hintze 2007).

De esta manera, el achicamiento del Estado que propuso el neoliberalismo, impactó de lleno en las historias de las mujeres entrevistadas. Patricia y Sonia, relatan cómo llegaron las políticas de ajuste a su vida:

El plan jefes y jefas de hogar me lo dieron en el año 2001, tiempo después de que tuve a Micaela. Este plan sale en los diarios para personas de bajos recursos y que no estaban empleadas y fui a anotarme para que me lo den. Igualmente no era que te lo daban y listo, sino que debías cumplir 6 horas diarias de trabajo en la Municipalidad. Nos pagaban miseria, eran solo $\$ 150$ por mes y nos explotaban. A mí no me alcanzaba para vivir, tenía a mi hija que criaba sin ayuda del padre, así que me la empecé a rebuscar sola por otros lados. Empecé en la calle... (Patricia 2015).

En ese momento no te aumentaban el sueldo cobraba $\$ 150$ del plan y $\$ 50$ por la Municipalidad, tenía que pagar un alquiler de $\$ 300$, no tenía para comer me daban la vianda. Me daban la bolsa de la mercadería de la Municipalidad que eran víveres secos que me duraban 5 días (Sonia 2015).

En consonancia con el énfasis en la atención de la pobreza, durante la primera mitad de la década de los '90 las políticas focalizadas en grupos social y biológicamente vulnerables fueron las intervenciones públicas asistenciales de mayor visibilidad. En la segunda mitad de la década del 90, los planes de empleo se presentaron 
como respuesta al acuciante problema de la desocupación. Con variaciones, constituyeron en general subsidios directos a desocupados (sujetos a capacitación o contraprestación laboral), creación de empleo público temporario (bajo modalidades de pasantías) y subsidios a la generación de empleo en el sector privado (Hintze 2007).

En relación a lo mencionado Montańa y Policastro (2012), expresan que por lo general, el estado ha ignorado la perspectiva de género al momento de diseñar las políticas sociales, reproduciendo asimetrías y discriminación económica a la mujer, sin redefinir las asignaciones simbólicas para ambos géneros.

\section{El patriarcado como organizador de la vida familiar}

"La familia como principal agente socializador configura el campo de las relaciones afectivas más profundas y constituye uno de los pilares de la identidad de un sujeto. De esta manera en el seno de la vida familiar es donde los sujetos tejen los lazos afectivos primarios, los modos de expresar las emociones, la vivencia del tiempo y, del espacio, las distancias corporales, el lenguaje, la historia de la familia grande, extensa, que comprende a las distintas generaciones que nos precedieron; es decir, todas las dimensiones humanas más significativas se plasman y transmiten en la cotidianeidad de la vida en familia" (Baeza 1999:1).

Las familias de origen de las entrevistadas se caracterizan por ser familias numerosas que están atravesadas por problemáticas de violencia, pobreza y, en algunos casos, situaciones de adicción. En varias ocasiones las mujeres relatan que se desprendieron de sus hogares desde muy adolescentes, pero más tarde por diferentes motivos debieron regresar.

Mi papá era empleado municipal y mi mamá nos criaba, éramos 8 hermanos...viví con el miedo a que la matara porque él era violento. También era alcohólico... Termine la primaria y no seguí más la escuela. Me puse de novia a los 15 años y a los 16 me fui de mi casa; mis papás nunca me dijeron nada, de hecho con mi mamá no teníamos una relación fluida y nos veíamos muy de vez en cuando. A los 20 , quede embarazada y obviamente no lo busque. Cuando mi pareja se enteró al principio no quería saber nada, pero después lo acepto y estuvimos juntos todo el embarazo. Él trabajaba en una empresa de limpieza y yo me quedaba en la casa donde alquilábamos. A los dos años de mi hija Micaela, nos separamos y me echo de mi casa porque tenía una amante, así que no me quedo otra alternativa que ir de nuevo a la casa de mi mamá. En ese momento me encontré sola con mi hija de 2 años, sin mantención, sin trabajo, con un plan y sin un lugar propio donde vivir, y para colmo mi hija se había enfermado y no tenía plata para comprar la medicación (Patricia 2015). 
Tengo 5 hermanas mujeres menores que yo, mi papá tiene 56 años y es mecánico en un taller automovilístico y mi mamá (Mabel) falleció cuando yo tenía 14 años. Así que tuve que dejar de estudiar y ponerme a trabajar para mantener a mi familia, ya que mi viejo no podía cuidarnos ni mantenernos porque se había tirado al alcohol (Soledad 2015).

En el caso particular de Sonia, vivió su niñez y adolescencia en la zona rural de La Pampa con su madre y con su padrastro, que falleció hace unos años por alcoholismo. Sonia tiene 10 hermanos, ella y su hermana mayor no eran hijas del seńor X. Sonia relata que se encontraban en situación de pobreza y además su padrastro abusaba sexualmente de su hermana mayor con quien tuvo un hijo; y también maltrataba a su madre. Alrededor de los 11 años escapa del campo junto a un tío materno que le brinda su ayuda.

... Y me acuerdo clarito que los patrones, por ahí ellos iban y llevaban mercadería y eran todos víveres secos para 15 días, la carne la sacábamos de ahí porque ahí carneaban. Había una bolsa de galletas que más de una vez estaba verde y tenías que comer lo que había...Y en la mesa notaba la discriminación que yo no era hija de él, porque estaban todos mis hermanos comiendo y primero le daba a los hijos de él y después a mí y yo le decía a mamá: Mamá tengo hambre, ¿puedo repetir? y ella me decía No, porque tiene que comer tu padre.

...Mi padrastro a mi mamá la golpeaba, con nosotros fue un ejemplar padre porque nunca nos puso una mano encima. Yo le tenía miedo porque él nos estaba criando para él...a mi hermana se la empezó a agarrar de chica...yo le tenía miedo...y mi mamá nunca lo vio porque ella era limpiar, lavar, planchar todo el día y mi hermana era más grande y se quedaba limpiando la casa...

...Mi padrastro falleció hace 8 años, él tomaba y le pegaba a mi mamá, con lo que tenía en la mano o con un palo le pagaba en la espalda o en los brazos en cualquier lado le pegaba...Yo me escape porque yo le tuve miedo a él, porque él me amenazo, me dijo vos abrís la boca y vas a ver lo que te pasa. Y él se la seguía agarrando a mi hermana, y yo dormía vestida con un calor que se partía la tierra y dormía envuelta con una sábana porque tenía miedo que se sacara la ropa y me agarrara. Andaba atrás de mi mamá, siempre tuve miedo... (Sonia 2015).

Los relatos develan como el sistema patriarcal, atraviesa toda la organización del grupo familiar. Si bien el patriarcado es una estructura invisible, se manifiesta a través de la desigualdad de poder en torno a las relaciones de género. En las familias de estas mujeres, los hombres tenían el poder de decidir sobre la vida de todos los 
miembros pero, especialmente, decidían sobre la vida de las mujeres y sus cuerpos, no como sujetos con derechos sino como objetos a utilizar en función de sus necesidades.

El hombre de la familia, reencarnaba la figura del patriarca. Su autoridad, ejercía el poder a través de la división sexual del trabajo. La esposa reservada al ámbito privado, realizaba el trabajo doméstico que contenía el cuidado de la casa, la crianza de los hijos y la atención del marido. Mientras que para el hombre, estaba reservado el acceso a los bienes a través del trabajo remunerado, tenía el privilegio de apelar al ámbito público, donde se obtienen los recursos indispensables para la reproducción de la vida familiar. A partir de allí, de ese lugar de poder, decidía y administraba el dinero. También ejercía todo tipo de violencia, especialmente el maltrato físico y sexual a las mujeres de la familia.

De esta manera, como se puede observar con la ausencia de intervención de las instituciones estatales, las leyes del patriarcado se impusieron en el seno de las familias sin ningún cuestionamiento.

Facio (2005) señala que en todos los sistemas patriarcales nos vamos a encontrar con una serie de características comunes; para comprenderlo debemos primeramente saber que tiene orígenes culturales y no naturales, pero por sobre todo requiere de la fuerza y el temor - en otras palabras la aplicación o amenaza del dolor- para mantener y reproducir los privilegios de aquellos que dominan. Dicha violencia se instala en los cuerpos de las mujeres quienes quedan sujetas al control sexual y reproductivo de los varones, en particular de aquel que se atribuye su dominio.

La cultura sexista y patriarcal, se instala como parte de la identidad de varones y mujeres reproduciendo roles y estereotipos de género que legitiman la violencia contra las mujeres. Las narraciones dejan ver como los vínculos de las familias de nuestras testimoniantes se volvían a reproducir a la hora de conforman una pareja y posteriormente tener hijos.

Era enfermo de los celos tenía que llegar a la hora que él me decía porque si llegaba dos o tres minutos después ya se enojaba. Hasta embarazada me agarraba de los pelos me arrastraba y me golpeaba; es hasta el día de hoy que me peino y me duele el cuero cabelludo... Me tenía que poner con el sin tener ganas y en esas ganas que no tuve también nació mi hijo...me tuve que poner porque él se tenía que sacar las ganas. Yo tenía miedo de que él se fuera con otra y me dejara sola con los nenes... entonces me tenía que poner...ese dolor no me lo voy a sacar hasta el día que me muera. Entonces, yo me tenía que aguantar eso por la luz, por el gas, por el techo, porque me ampliaba la casa, no es que yo pensaba en la comodidad sino que pensaba en mis hijos. Para que no estuviera en la calle y con mis hijos rodando por ahí (Sonia 2015). 
Yo estuve muy enamorada de él, pero me hizo mucho daño. El me pegaba, me maltrataba y me vivía (Soledad 2015).

El patriarcado le ha inculcado a Sonia, como a muchas otras mujeres, que la sexualidad masculina tiene un origen natural, que es necesario satisfacer y que las mujeres son las responsables directas de esa satisfacción. Dentro de este escenario de tortura, los sentimientos y deseos se van adormeciendo; y las mujeres interiorizan la idea de que su cuerpo ya no les pertenece, que ya no tienen poder de decisión sobre él. Ese cuerpo enajenado pasa a convertirse en una máquina para satisfacer los deseos sexuales del hombre y en la práctica se confirma la idea de que la sexualidad femenina se subordina a la sexualidad masculina.

Tal y como seńalan Navarro y Celay (2002) una de las manifestaciones psicológicas del patriarcado se observa en la falta de autoestima de las mujeres, inducida por la educación y la violencia del entorno. Esto se traduce en una permanente actitud de resignación, de "sacrificio" mal entendido, de búsqueda permanente de la aprobación de los demás (especialmente de los varones), no tener confianza en las propias fuerzas, estar permanentemente inseguras de sí mismas, sentirse culpables de lo que les pase a otros, como por ejemplo a sus hijos.

Los autores ponen en evidencia el miedo a la libertad que tienen muchas mujeres inmersas en situaciones de violencia, que desarrollan cierta dependencia psicológica hacia los hombres violentos, y romper con ello requiere de desnaturalizar y poner en cuestión normas, creencias y valores que dan lugar a prácticas violentas. Sonia lo cuenta de esta manera:

yo mentía cuando me golpeaba, inventaba muchas excusas...él me daba puñetazos en las piernas y los brazos y me decía ahora anda y contale a tu amigas y vas a ver cómo te va a ir...Me trataba verbalmente mal, me desgastaba psicológicamente en todo, no me daban ganas de hacer nada. Te sentís obligada a seguir porque no tenés otra cosa...Entonces yo tenía que hacer todo lo que él decía. Y un día una compañera me dijo que no tenga miedo, deja que te pegue en la cara que te desfigure y ahí llamas a la policía y así te lo sacan de la casa. Sino tenés desfiguración de rostro la policía no te va a creer. Y es verdad, me hice romper toda la cara, los pómulos, la boca, que por ahí tengo un tajo largo. Se me cayó la boca en pedazos. Ese día lo encare y le tire un grabador, y le dije no me pegues más, me tenés cansada Ariel, y ahí me agarro contra la pared, me pegaba piñas... y yo puse la cara. Salí con la cara llena de sangre con mi hijo, llamé a la policía y ahí se lo llevaron preso.

Antes había ido a la policía pero no me creían...esos moretones te lo podes haber hecho vos me dijo el oficial de la Seccional Primera en aquellos años. Cómo sabemos si te pego él, capaz que vos viniste y te pegaste con un martillo, y dijiste lo quiero denunciar porque hay 
mujeres que andan con otros tipos y con tal de sacarlo de la casa. Y yo le decía no es así, y bueno pero como hacemos para creerte y bueno podes conseguir testigos... (Sonia 2015).

\section{Encuentro con el Prostituyente}

En el pensamiento colectivo, la palabra prostitución está asociada a la imagen de una mujer, pero no habría mujer prostituida sin un hombre que demandara la prostitución. No es casual, que la imagen del cliente ha sido ocultada en el imaginario de la explotación sexual. Cabe señalar que la prostitución, no debe ser definida como el oficio más antiguo del mundo sino como la actividad que responde a la demanda más antigua del mundo: la de un hombre que quiere acceder al cuerpo de una mujer y lo logra a cambio de un precio (Cobo Bedia, 2014:3).

El patriarcado silencia el rol del cliente, situándolo en una posición casi secundaria en la problemática. Cada vez que se habla de prostitución todas las referencias están orientadas hacia las mujeres; se invisibiliza la figura del prostituyente, descontextualizando la vinculación de la estructura patriarcal que la contiene.

En el ejercicio de la prostitución, todas las mujeres se exponen a experiencias potenciales de maltrato, denigración y humillación, e incluso se enfrentan con el temor a lo desconocido. Es importante señalar, que en el contacto genital con el hombre, las mujeres se encuentran expuestas a situaciones que las violentan en forma continua (cansancio de su cuerpo, desagrado de ciertos aspectos del cliente o prácticas sexuales riesgosas) pero que desde su perspectiva estas agresiones son representadas como aspectos negativos que forman parte de la cotidianeidad-normalidad de este contexto.

Dicho lo anterior, en el encuentro íntimo con el otro-desconocido se presentan diferentes situaciones estresantes, que dan origen al conflicto y que la mujer debe aprender a negociar para salir ilesa de él. Las entrevistadas, señalan que los ejemplos más significativos son cuando los hombres se presentan agresivos, cuando no están higienizados o han ingerido alguna sustancia, y otra de las situaciones conflictivas, cuando se niegan a utilizar el preservativo y pagar por la actividad.

Los encuentros sexuales con sus clientes, se describen a partir del desagrado y el desprecio que les produce la relación sexual aun cuando se trate de un cliente habitual o un desconocido.

...Me da asco y siento asco del hombre, me humillo como persona, me humillo como mujer. Yo nunca tuve ningún sentimiento lindo con esos tipos...les tengo asco y bronca. El hombre me humilló moralmente. Conseguí una persona mayor, era un asco porque me sentía violada. Me tenía que acostar y ponerle la boca...abrirle las piernas y me decía 
no tengas vergüenza...el tipo te va haciendo a que hagas esas cosas. No tengas vergüenza sácate la bombacha, sácate el corpiño y me quedaba como una tabla dura...el tipo se tiraba arriba se ponía un forro y me hacia lo que él quería...me daba asco porque ya de por si es una violación... y bueno terminaba y hacia lo que tenía que hacer el tipo y ya está... el me daba la plata y era la plata fácil pero a la vez no es plata fácil porque la humillación que siente la mujer, el asco no te lo saca nadie. Cobraba $\$ 300$ y yo capaz que estaba 20 minutos con la persona en la habitación. Era plata, imagínate que me bancaba el alquiler y le agarraba gusto a la plata que era plata fácil pero vos pagabas el alquiler y te quedabas seca ¿y que te quedaba? Te quedaba lo que te había hecho el tipo, que era asco. Y te largabas a llorar...yo hasta el día de hoy me acuerdo y me da asco (Sonia 2015).

...A veces estaba en el momento ese y me daba tanto asco que lloraba....porque te da rabia de que no querés estar con cualquiera...y lo tenés que hacer. La mayoría de los hombres venían higienizados pero por ahí me sabía tocar algún sucio, de ultima vos podías elegir si ya habías trabajado le decías que no. Los del campo eran por ahí los que venían más sucios pero ellos traían más plata, venían con toda la plata y traían para gastar. Yo les sabia decir al padre de los chicos míos que yo sabía salir llorando de ahí, me daba bronca de estar ahí, del asco de estar acá y venirme caminando a las 4 de la mańana sola... Yo a la gente que siempre le tuve miedo, le decía que no por más que me faltara la plata. Yo tuve suerte de poder decir que no con los sucios. En esos momentos que yo a veces me largaba a llorar o estaba mal en el momento en que estaba con el hombre ellos ni se daban cuenta (Marta 2015).

Había veces que me hacia la borracha y la que no aguantaba para que no me exigieran hacer nada. Como así también, tengo situaciones que pase que no quisiera ni volver a recordar, ni volver a vivir (Soledad 2015).

Marisa Ortiz (1998) explica que el mecanismo de disociación en las relaciones con sus clientes, les permite separar temporalmente la relación YO-CUERPO; de esta forma logran sobrevivir a la repulsión física que les produce el contacto con algunos clientes y a la doble moral que socialmente tienen que jugar, la de mujer (madre-señora) y la de prostituta. A pesar de los mecanismos de disociación y formas de control que adoptan con sus clientes, algunas no dejan de sentir una gran frustración, presión moral y resistencia física al establecer sus contactos sexuales, sobre todo, al establecer estas situaciones de manera diaria y sin otras alternativas. Ante el encuentro con un hombre, las mujeres siempre deben estar alertas sean o no clientes habituales. Puede ser que el encuentro se desarrolle con normalidad donde se cumpla todo lo pactado antes de la relación sexual, como la higiene, el uso del preservativo, la forma de trato, el lugar de encuentro y el pago adelantado, pero no siempre sucede lo que se pactó. La atención de alerta se produce cuando los clientes 
se presentan habiendo ingerido alguna sustancia o cuando se acercan y generan desconfianza a la mujer. Esta actitud se desarrolla a partir de las experiencias traumáticas que han sucedido en contextos de prostitución. Todas narran experiencias que no han querido vivir, por eso desarrollan actitudes de cuidado ante alguna situación sospechosa.

...Yo una vuelta estuve ahí en el mate, en la Luro y se baja un tipo de un remis y me dice yo vivo acá a dos cuadras veni, vamos...y me dice tengo miedo que la policía nos esté mirando o tu marido, y le digo no, mi marido no está y la policía no la veo por ningún lado. Cuando iba caminando me dice adelantate que yo voy a orinar y para ese momento ya habíamos hecho una cuadra, faltaba una más... ya ahí desconfiaba. Había unos departamentos que estaban sin terminar, y le digo ¿y dónde está tu casa? Me dice ¿que estas apurada? No, pero yo tengo que seguir laburando. Es acá, ¿que estas de sereno? No, vos subí. No págame acá en la luz porque allá dentro no hay luz. Ya te voy a pagar, si acá tengo la billetera. Págame porque si no me vuelvo. Y saca un revolver debajo de la ropa y me dice metete adentro, así que tuve que entrar. Subimos una escalera caracol y me dice sacate la ropa y le digo no, la ropa no me la voy a sacar. Si querés plata yo no tengo recién llego. No me hagas nada porque yo tengo a mis hijos que me están esperando en mi casa, y me dice bueno, vos mira, hizo lo que tenía que hacer y terminó. Y me dice cuando vos sientas el tropel recién ahí baja. Yo muchas veces tenía desconfianza. Venían muchas veces consumidos o te invitaban a consumir (Marta 2015).

Del bar no me iba con cualquiera. Una sola vez... estábamos con mi amiga y dos hombres "clientes" tomando algo en el bar. Después de un rato, mi amiga se va a la habitación con el chico y yo me quede en el bar con el otro hombre. En un momento nos fuimos del bar. En el camino me empezó a pedir que tengamos relaciones sin preservativo; así que le dije que no, que yo no me manejaba así. Ahí fue donde el hombre me abrió la puerta del auto y me tiro, dejándome abandonada por unas calles oscuras y muy lejos del bar (Soledad 2015).

El relato de Soledad, evidencia los riesgos a los que se expuso al salir del ámbito privado donde tenía cierto resguardo de sus compañeras. Allí en la calle aumentaba la probabilidad de que los hombres atenten contra su integridad física exponiéndose a la violación, contagio de enfermedades de trasmisión sexual, embarazos no deseados o la misma muerte.

Esta actividad de sometimiento y maltrato, es considerada en muchas partes del mundo necesaria para satisfacer la sexualidad masculina, reivindicando de esta manera el ejercicio de la violencia de género, la desigualdad y vulnerabilidad femenina que está siendo naturalizada por hombres, mujeres y niños/as. La naturalización de la prostitución y su uso por parte de los "consumidores", da lugar a que la brecha 
desigual "hombre-mujer" se amplíe generando una exclusión laboral, percibiendo como única posibilidad de salir adelante el camino de la prostitución.

\section{Reflexiones sobre la prostitución como trabajo}

La problemática de la prostitución implica una serie de debates respecto si debe ser reglamentada como trabajo sexual o abolida del sistema social. Argentina tiene, desde el año 1936, una posición abolicionista que actualmente constituye el discurso hegemónico en el debate sobre prostitución.

Dentro del movimiento feminista, quienes sustentan el enfoque reglementarista propugnan el concepto de trabajadoras sexuales. Afirman que en la prostitución se intercambian servicios por dinero, alguien ofrece una mercancía alguien paga por ella. Cualquier contrato entre adultos en que haya sexo y consentimiento debe ser respetado y tal vez legitimado. También sostienen que la legalización acabaría con las mafias y los problemas que sufren las trabajadoras sexuales, como el tráfico y el estigma que proceden de la falta de reconocimiento social, no de las características intrínsecas al oficio (Álvarez, 2012:58).

Mientras que el abolicionismo, habla de mujeres en situación de explotación. Dentro de esta corriente se concibe a la prostitución como violencia contra las mujeres y afirman que no es comparable a ningún trabajo. La prostitución se encuentra anclada en la desigualdad de género, y a partir de allí, afirman que las mujeres son víctimas de una sociedad capitalista y patriarcal.

Expuestas las diferencias de una postura y la otra, podemos observar que en el discurso de las entrevistadas ninguna conoce los debates que se están dando a nivel nacional, latinoamericano y mundial sobre su situación de prostitución. Ninguna de ellas, tenía conocimiento sobre estas reflexiones dentro del movimiento feminista. Pero a la hora de indagar sobre la visión que considera a la prostitución como trabajo y cómo las mujeres se inician, todas coinciden en que lo hacen por falta de trabajo, de formación educativa, por condiciones precarias de salud, por no tener acceso a una vivienda, por falta de alimentos, todos aspectos que producen situaciones de derechos humanos vulnerados.

Sonia, Marta y Soledad lo expresan de esta manera:

...No sé, nunca escuche este tema... que sea un trabajo. En su momento cuando te toca hacer eso no tenés otra opción... Para mí no es un trabajo, no es un trabajo que una persona te basuree que te tenga que pagar y decirte haceme esto, haceme lo otro... El trabajo es que vos hagas lo que vos sientas como yo atender a los chicos, higiene, la limpieza de acá. Hubiese preferido, siempre dije, de estar fregando zócalos...limpiando a hacer eso... Para 
mí no tendría que estar legalizado, si quieren hacer eso...como que eso es un trabajo...No es nada honrado, no es un trabajo...es lo más bajo que hay para mí (Sonia 2015).

La prostitución es sobrevivir, lamentablemente si tuviera que volver a hacerlo, lo haría solo por ellos (hijos) y para darles todo a ellos; no me permitiría que sufran porque les falte algo (Soledad 2015).

...A comparación de otros trabajos que yo he tenido, la prostitución es fácil en el sentido que yo no tenía que cumplir un horario, si estaban enfermos lo chicos faltaba, no tenía una patrona...en la prostitución vos hacías lo que tenías que hacer y te pagaban, pero cuando vos te subís a un auto a veces te vas tranquila porque es gente conocida pero a veces te levantaba gente desconocida y vos ibas pensando con quien te vas y si va a estar todo bien. Para mí la prostitución es como un trabajo y las mujeres necesitan ayuda. Yo creo que la prostitución existe porque hay falta de trabajo. A mí me pasó porque no tenía trabajo, tenía uno y me fue mal, busque y no conseguía... Yo si pudiera elegir un trabajo, a mí me gustaría vender ropa, andar casa por casa vendiendo ropa (Marta 2015).

Las mujeres ponen en evidencia que el comercio sexual no es la elección menos mala sino que es el único horizonte posible, en un mundo donde la prostitución esta naturalizada como forma de subsistencia de las mujeres, en el momento que el Estado deja de ser el organizador de la vida social.

\section{Reflexiones Finales}

Defagó y Riviera (2007) señalan que la situación socioeconómica de la familia de la mujer en situación de prostitución, condiciona en gran medida sus posibilidades reales de desarrollo. Para una familia en situación de pobreza, el principal problema es la subsistencia, por lo tanto, sus esfuerzos están dirigidos a la obtención del alimento, la vivienda y el vestido; la recreación es casi nula y la salud muy precaria, las posibilidades de educación de sus miembros, limitadas al máximo y, en gran medida, la ulterior posibilidad de empleo. En general, la condición psicoafectiva está caracterizada por indiferencia y madurez temprana de sus miembros y "...el ciclo de la vida familiar está ligado a las fluctuaciones del desarrollo de la economía doméstica”.

Por consiguiente, las familias se ven presas de los mecanismos del mercado capitalista que saca provecho de su condición de vulnerabilidad, especialmente de las mujeres que se ven más expuestas. Esto no solo sucede porque se enfrentan a la explotación capitalista sino también porque deben hacer frente a la explotación 
patriarcal. Por un lado sufren por su carácter de género (ser mujer) y por otro lado, en su carácter de clase (por su pertenencia a sectores populares).

El Estado como regulador de la vida social tiene el deber de respetar, proteger, promocionar y garantizar los derechos humanos fundamentales que establece la constitución nacional. Es allí, frente a la organización del Estado y la forma de sus políticas públicas, es que la ciudadanía debe reclamar y exigir por la restitución de sus derechos.

Del mismo modo, las entrevistadas coinciden que han dejado de prostituirse cuando sus condiciones económicas han mejorado. Sonia dejo de salir con sus clientes cuando llego a ser parte de la planta permanente Municipal, Marta cuando consiguió trabajar cuidando abuelos en un geriátrico y algunos empleos de limpieza, Soledad cuando se clausuró el cabaret y consiguió trabajo en el Estado Provincial a través de un monotributo; y Patricia cuando conoció a su pareja con el que formó una familia. Además, ha colaborado la existencia de Programas del Estado Nacional que permiten satisfacer las necesidades básicas de las familias y han brindado un respiro a las mujeres para no depender puramente de los ingresos que provenían de la prostitución. Las principales políticas fueron la Asignación Universal por Hijo, Pensión por Madre de 7 Hijos y las Pensiones no contributivas.

En otras palabras para ninguna de ellas la prostitución fue un trabajo, es decir, una alternativa laboral posible de continuar realizándola; en el momento en que aparecieron otras alternativas decidieron abandonar la explotación sexual.

Gracias al acceso al empleo formal o informal y las políticas estatales las familias se encuentran en mejores condiciones económicas y sociales. Las jefas de hogar, tienen más libertad para proyectarse en el futuro lejos de la prostitución.

Para finalizar y haciendo referencia a la prostitución como trabajo, retomó las palabras de las propias protagonistas para describirla:

yo creo que la prostitución existe porque hay falta de trabajo (Marta 2015).

Me da asco y siento asco del hombre, me humillo como persona...para mí no es un trabajo que una persona te basuree (Sonia 2015).

La prostitución es sobrevivir (Soledad 2015).

Si bien las mujeres, que brindaron su testimonio, han salido de la prostitución las huellas de esa experiencia en sus memorias y en sus cuerpos aún persisten. 


\section{Bibliografía}

FACCIO, Alda y FRIES (2005), Feminismo, género y patriarcado. Extraído el día 08/02/2016 de http://centreantigona.uab.es/dox/ articulos/feminismos.

ALVAREZ, Ana (2012), La prostitución de mujeres, una escuela de desigualdad humana. Revista Europea de Derechos Fundamentales ISSN 1699-1524 Núm. 19/1er Semestre, 49 - 74. Espańa.

BAEZA, Silvia (1999), La intervención familia y escuela. Extraído el día 09/05/2015 de http://www.redsistemica.com.ar/baeza.htm

COBO BEDIA, Rosa (2014), La prostitución entre el capitalismo neoliberal y el patriarcado. Extraída el día 02/03/2016 de http://www. revistapueblos.org/?p=15606

COMISIÓN ECONÓMICA PARA AMÉRICA LATINA Y EL CARIBE (2012), Panorama Social para América Latina. Extraída el 1711-2014 de http://www.cepal.org/cgi-bin/getProd.asp?xml=/prensa/ noticias/comunicados/8/48458/P48458.xml\&xsl=/prensa/tpl/p6f. $\mathrm{xsl} \&$ base $=/$ tpl/top-bottom.xsl

DEFAGÓ, María Belén y RIVIERA, Elisa (2007), Prostitución un camino de desencuentros. Trabajo Final de investigación para cumplimentar la carrera de Servicio Social en el Instituto del Rosario. Escuela de Servicio Social Cardenal E. Ruffini. Villa María, Argentina.

ELIZALDE, Silvia; FELITTI, Karina y QUEIROLO, Graciela (2010),: Género y sexualidad en las tramas del saber. Revisiones y propuestas, Libros del Zorzal, Buenos Aires, Argentina.

FALCÓN, C. (2010), Usos y abusos de drogas en contextos de prostitución. Madrid. España.

FONTELA, Marta (2004), (Extraído el día 17-11-2014). http://www. agendadelasmujeres.com.ar/

HINTZE, Susana (2007), Políticas Sociales Argentinas en el cambio de Siglo, conjeturas sobre lo posible. Espacio. Buenos Aires - Argentina.

LAMAS, Marta (2014), ¿Prostitución, trabajo o trata? (Extraída el día 17-11-2014) http://www.nexos.com.mx/?p=22354

LIPSZYC, Cecilia (2014), Mujeres en situación de prostitución: ¿trabajo o esclavitud sexual? Extraída el día 10/06/2014 de la siguiente página: http://ispm.org.ar/pdfs/mujeres_situacion_prostitucion.pdf.

MOLINA, María Lourdes (2008), Explotación Sexual, Evaluación y Tratamiento. Buenos Aires: Editorial Dunken. 
MONTAÑA, Érica y POLICASTRO, Betsabé (2012) Empleo y Políticas Sociales. Programas, experiencias y movilización de mujeres. Universidad Nacional de La Pampa. Santa Rosa La Pampa.

NAVARRO, Mariano y CELAY MONTERO, Luisa (2002), El patriarcado: una estructura invisible. Extraído el día 18/12/2015 de http:// www.stopmachismo.net/marmar2.pdf

OMS (2009), Las mujeres y La Salud. (Extraído el día 18/11/2014) http://whqlibdoc.who.int/hq/2009/WHO_IER_MHI_STM.09.1_ spa.pdf?ua $=1$

OMS (2009), (Extraído el día 18/11/2014) http://who.int/mediacentre/ factsheets/fs334/es/

ORTIZ, Mariza (1998), Soy una mujer de ambiente. $1^{\circ}$ edición. Ed. Universidad de Costa Rica. San José.

QUIROGA, Ana y RACEDO, J. (1988), Critica de la vida cotidiana. Buenos Aires: Ediciones Cinco.

RIVIERA, Elisa (2011), La vida cotidiana de Mujeres en situación de Prostitución. Prácticas y Representaciones. El caso de Villa María. Trabajo Final de Grado para la Licenciatura en Trabajo Social. Villa María, Argentina.

SANCHEZ, Sonia y GALINDO, María (2007), Ninguna mujer nace para puta. Buenos Aires. Lavaca.

SCOTT, Joan (1990), El género: Una categoría útil para el análisis histórico. American Historical Review. Estados Unidos.

\section{Fuentes Primarias}

FOLMER, Carolina y RUSAS, Noelia (2015), Entrevistas realizadas a Marta, Patricia, Sonia, y Soledad. Santa Rosa, La Pampa.

Recibido: 22/05/2016

Aceptado: 21/06/2016 